\title{
Desigualdades en educación superior: una mirada desde Europa
}

\section{Inequalities on higher education: a look} from Europe

\author{
Lola Frutos Balibrea \\ Profesora Titular del Departamento de Sociología. \\ Facultad de Economía y Empresa. \\ Universidad de Murcia. \\ E-mail: $\underline{1 \mathrm{lb} @ u m . e s}$
}

Todas las sociedades a lo largo de la historia necesitan que las personas peor situadas acepten que su situación es consecuencia de una elección racional decidida por el individuo, tal y como describe la Teoría del Capital Humano, y no se rebelen. La educación en la actualidad está sirviendo de legitimación de la desigualdad social de la misma forma que en otras épocas históricas procedía de la ideología, religión, leyes, etc. La inversión en educación atribuye al individuo la decisión de optar - 'elección racional'por la educación siguiendo, al menos en teoría la denominada "igualdad de oportunidades" y quien alcance el nivel más elevado (universitario) no sólo ganará más salario, sino que obtendrá un mayor rendimiento en el mercado de trabajo. ¿Hasta qué punto es cierta esta afirmación?

Se trata de una teoría que todavía hoy tiene un gran calado en los organismos internacionales y en la sociedad, pero no tiene en cuenta la estructura social y la superposición de las desigualdades, independientemente de la voluntad de los individuos, tal y como lo demuestra la evidencia empírica de la investigación sociológica. En efecto, el género, la clase social, el hábitat, el territorio, la religión, la nacionalidad, etc. están en la base donde se asienta la desigualdad.

Obtener un título universitario es más rentable en el mercado de trabajo que no tenerlo y, en general, hay correlación entre el nivel educativo alcanzado y el salario, pero en España -tras la crisis-, si bien es más fácil encontrar trabajo con un nivel educativo elevado no implica que los universitarios se coloquen como técnicos sino como administrativos, ganando menos y cada vez importa menos que antes ir o no a la universidad (Frutos, 2015: $583)$. 
La transición de la educación al mercado de trabajo viene recibiendo desde hace tiempo una especial atención por parte de diversos organismos internacionales y del lado epistemológico hay una larga tradición de estudios. En efecto, los trabajos previos en torno a la transición de la educación a la vida laboral lo reflejan tanto de manera general (Shavit, Müller, 1998; Stern, Wagner, 1999) como específicamente referida a los titulados superiores (Kivinen, 1997; Teichler, 1998).

Paul Ryan (1999) subraya que los patrones de transición deberían incluir como dimensiones básicas la duración de la transición, el nivel de empleo y desempleo, la calidad del empleo, el papel de la educación y las desigualdades sociales. Un estudio que ha recogido y analizado información sobre la inserción laboral de la educación superior en once países europeos -incluida España- es el llamado proyecto CHEERS (Careers after Higher Education: a European Research Study) cuyos resultados han sido presentados en nuestro país por José García Montalvo (2001).

Otros estudios hacen referencia a los conceptos de itinerarios y trayectorias, para destacar la dimensión del proceso de acceso al mercado de trabajo, condicionado por la estructura, frente al enfoque económico tradicional que habla de las carreras como procesos de ajuste entre el esfuerzo individual en un contexto de competencia (García Blanco y Gutiérrez, 1996; Gutiérrez, 1997, Casal et. al, 2006).

Así mismo son numerosos los estudios sobre la movilidad a lo largo de la vida laboral, en función del nivel educativo. Ejemplos son los de Andrés (1991), Sánchez, Peraita, y Huguet (1995), Toharia (2001), en los que subrayan que a mayor nivel educativo hay una mayor probabilidad de movilidad laboral.

Referido exclusivamente a los egresados de la universidad, se enmarca el proyecto de investigación "Trayectorias académicas y laborales de los egresados en tres universidades: Santiago, UNED y Murcia: diferencias de género", Frutos (2004) y los estudios sobre graduados españoles y catalanes realizados por el GRET de la UAB (Fachelli y Planas, 2011, 2014; Fachelli et al, 2014, Torrents et. al, 2015; Fachelli, 2018). 
En perspectiva comparada y diacrónica, las tendencias que se han dibujado en la UE en las tres últimas décadas del siglo XX indican que, si bien el volumen del alumnado se ha más que duplicado, el volumen de la presencia de mujeres en la educación superior se ha multiplicado por tres. Los países donde el crecimiento ha sido más acentuado coinciden con aquellos donde los procesos de incorporación de amplios segmentos de sucesivas cohortes a la educación superior comienzan más tardíamente, esto es, en Grecia, Irlanda, España y Portugal, países, por otra parte, que son los que registran los mayores aumentos en el número de mujeres, ya que el alumnado femenino se ha multiplicado por 5 en Irlanda y Portugal y casi en la misma proporción en Grecia y España. Por el contrario, el crecimiento - tanto global como del número de mujeres- ha sido menos intenso en Bélgica, Dinamarca, Francia, Italia, Holanda y Alemania.

Si observamos las cifras para el conjunto de la UE en el curso 1970-71, sólo 15 de cada cien personas accedían al nivel superior del sistema educativo. Por países, los valores más elevados - por encima del 18\%- correspondían a Francia, Dinamarca, Holanda y Suecia, mientras que sólo en España y Portugal la tasa global se situaba por debajo del 10\% (8,7\% para España).

Veinte años después, en el curso 90-91, la tasa bruta de participación en la educación superior en los países de la UE es del 35,4\%; en ese curso en España es del 36,7\%, quedando Finlandia en el extremo con casi un 50\%, y en el otro extremo Portugal, con un $23,2 \%$.

En el curso 1999-2000, la tasa bruta de participación es ya del 62,4\%, cuarenta y siete puntos más que en el curso de 1970-71. Es espectacular el incremento de la tasa en España $-57,6 \%-$, si bien Finlandia sigue situándose muy lejos de la media, con una tasa de casi el $84 \%$.

El último informe publicado en 2018 (Sistema estatal de indicadores educativos), referido al curso 2015-16, señala los países con mayor número esperado de años de escolarización: Finlandia (20 años), Suecia, Países Bajos y Dinamarca (19 años). A continuación, se sitúa España con 18 años, junto con otros ocho países, entre los que están Alemania y Reino Unido. Con 17 años aparecen cuatro países, entre ellos, Francia y Portugal, y con 16 años aparecen cinco, entre ellos, Italia. Rumanía (14) y Malta (15) que presentan los valores más bajos. El número de años esperados está influido en gran parte por el nivel de escolarización alcanzado en las edades postobligatorias. 
Así, considerada la tasa neta de escolarización entre 15 y 24 años, destaca Eslovenia con $76,2 \%$, seguida por Países Bajos (72,6\%) y Dinamarca (70,0\%). Otros ocho países superan el $65 \%$, entre los que aparecen Finlandia $(68,0 \%)$ y España $(67,8 \%)$. Por debajo del $60 \%$ se sitúan nueve países, entre ellos Reino Unido $(58,1 \%)$ e Italia $(57,9 \%)$.

En el curso 2015-16, la esperanza de vida en educación en España de un alumno de cinco años de edad es de 18,7 años. Las comunidades autónomas con los valores más altos son La Rioja $(22,6)$, Comunidad de Madrid $(20,1)$ Castilla y León $(19,7)$ y País Vasco $(19,6)$. En todas las comunidades autónomas, el número de años esperados en educación y formación desde los cinco años ha aumentado desde el curso 2010-2011.

En el curso 1999-2000, el porcentaje de la población femenina es 10 puntos más elevado que el de los varones en la mayoría de los países de la UE. No obstante, hay notables diferencias entre países: así en Suecia se da un mayor gap sexual, pues hay 25 puntos de diferencia entre sexos a favor de las mujeres.

En cuanto a la edad, el nivel de formación en España es mucho mejor en la población joven de 25 a 34 años que en la de más edad de 55 a 65 años. En el año 2013, los resultados medios de España en la Enseñanza Superior alcanzan un porcentaje del $41,1 \%$ en la población joven por tan sólo la mitad en la población de 55-64 años (20,2\%). Si comparamos este fenómeno con el resto de niveles de estudio es reseñable la existencia de un sistema educativo muy polarizado, pues hay jóvenes de 25 a 34 años con estudios sólo obligatorios $(27,6 \%)$ o incluso menos $(7,6 \%)$ en la primera etapa de educación Secundaria.

Respecto a la presencia femenina, aunque la paridad se alcanza a mitad de los años ochenta, se da una notable asimetría entre mujeres y hombres en lo que se refiere a la distribución por ramas de enseñanza, ya que las universitarias se concentran en las ramas de Humanidades y Ciencias Sociales y son muy pocas las que optan por las carreras Técnicas. 


\section{Las contribuciones al monográfico}

En este monográfico se publican tres trabajos de gran interés para la investigación sobre la desigualdad educativa en la educación superior.

El primer artículo, escrito por Cecilia Blanco y Erika Oinonen, titulado "Higher education policies and questions of social (in)equality: cases of Argentina and Finland", aborda la actuación de las políticas públicas de Educación Superior, a partir de un análisis cualitativo, genealógico, de documentos que nos permite interpretar similitudes y diferencias entre un Estado de Bienestar basado en la educación, la salud y en los derechos sociales como señalaba Marshall o la ausencia del Estado y el protagonismo del Mercado en su lógica neoliberal, cuestión que no está polarizada en un único país sino que en esta fase global neoliberal afecta al núcleo originario de los países que desarrollaron en la etapa Fordista el Estado de Bienestar, cuando se ensancharon las clases medias y el capitalismo ofrecía un rostro más humano.

El segundo artículo de Sandra Fachelli titulado "El rol de la educación superior en la movilidad ocupacional intergeneracional: análisis comparado entre Argentina y España" indaga la influencia de la educación con relación a la movilidad intergeneracional (origen de clase y destino a partir de la educación), considerando la movilidad intergeneracional tanto en España como en Argentina. Ofrece un gran interés al introducir la variable género de manera transversal, es decir, parte de la superposición de las desigualdades. La utilización de una metodología cuantitativa basada en el análisis logístico binario le otorga una gran contundencia a los resultados, mostrando la importante magnitud en que los estudios superiores contribuyen a alcanzar altas posiciones ocupacionales. La investigación de Sandra Fachelli invita e interpela a la sinergia colectiva y es innovadora por adoptar otras dimensiones de representación de resultados, así como el hecho de incorporar el género, tanto de los graduados/as como el de sus padres que otras investigaciones socioeconómicas no lo han hecho tradicionalmente.

Por último, el tercer artículo, con el título "Efectos del origen social familiar en el logro educativo en el nivel superior en Argentina y México. Caminos diferentes, desigualdades similares" escrito por Paula Boniolo, Pablo Dalle y José Navarro Cendejas, tiene como objetivo determinar los factores adscriptivos -clase de origen y lugar de nacimiento- a la hora de obtener el título en Educación Superior en dos territorios muy distintos por la historia: Argentina y México, así como el rendimiento de los títulos en la posición social adquirida. Tras el marco teórico basado en la relevancia de la estructura social analizan fuentes secundarias para aproximarse a esta doble realidad, utilizando una metodología 
multivariante por etapas para analizar los factores determinantes que subyacen en los dos países. Concluyen, como factor predictivo de logro social, la gran importancia de la clase de origen y el aumento de la desigualdad de oportunidades especialmente para la población con orígenes en las clases populares.

\section{Bibliografía}

ANDRÉS, J. (1991). El nivel de los estudios como factor explicativo del desempleo de los ingresos y de la movilidad laboral, Madrid, CES.

BLANCO, C. OINONEN, E. (2019). "Higher education policies and questions of social (in)equality: cases of Argentina and Finland", Revista de educación y derecho, 19, 1-22. BONIOLO, P. DALlE, P. NAVARRO CENDEJAS, J. (2019). "Efectos del origen social familiar en el logro educativo en el nivel superior en Argentina y México. Caminos diferentes, desigualdades similares", Revista de educación y derecho, 19. 123.

CASAL, J. GARCÍA, M. MERINO, R. QUESADA, M. (2006). “Aportaciones teóricas y metodológicas a la sociología de la juventud desde la perspectiva de la transición", Papers, Revista de sociología, 79, 21-48.

FACHELLI, S. PLANAS, P. (2011). "Equidad y movilidad intergeneracional de los titulados universitarios catalanes", Papers, Revista de Sociologia, 96 (4), 1281-1305.

FACHELLI, S. PLANAS, J. (2014). "Inserción profesional de los universitarios : de la expansión a la crisis", Revista Española de Sociología (RES), 21(2014), 69-98.

FACHELLI S. TORRENTS, D. NAVARRO-CENDEJAS, J. (2014). “¿La universidad española suaviza las diferencias de clase en la inserción laboral?", Revista de Educación; 364, 119 - 144.

FACHELLI, S. (2018). “La movilidad ocupacional de los graduados en las universidades públicas catalanas", Revista de educación y derecho,17, 1-32.

FACHELLI, S. (2019). "El rol de la educación superior en la movilidad ocupacional intergeneracional: análisis comparado entre Argentina y España”, Revista de educación y derecho, 19, 1-26.

FRUTOS BALIBREA, L. et al. (Coordinadora e investigadora responsable) (2003). Diferencias de género en el alumnado egresado de la universidad y su inserción laboral (itinerarios académicos y laborales de mujeres y hombres), Estudio comparativo de la Universidad de Murcia, UNED y Santiago de Compostela. Proyecto de investigación de $\mathrm{I}+\mathrm{D}+\mathrm{I}$. 
FRUTOS BALIBREA, L. (2004). "Educación Superior e inserción laboral desde la perspectiva de género", Reflexiones Sociológicas (Pp.151-176), Madrid, CIS.

FRUTOS BALIBREA, L. (2015). Títulos, trabajos y profesiones. En: Cristóbal Torres: España 2015. Situación Social, Madrid, CIS.

GARCÍA BLANCO Y GUTIÉRREZ, R. (1996). "Inserción laboral y desigualdad en el mercado de trabajo: cuestiones teóricas", REIS, $\mathrm{n}^{\circ} 75$.

GARCÍA MONTALVO, J. (2001). Formación y empleo de los graduados de enseñanza superior en España y en Europa, Instituto Valenciano de Investigaciones Económicas, Bancaja.

KIVINEN, O. (1997). "Graduate Credentials in a Changing Labour Market, Higher Education in Europe", Vol. 22, number 4.

RYAN, P. (1999). The School-to-Work Transition: Issues for Further Investigation. Elaborado para Education and Training Division, DEELSA, OECD, Paris.

SHAVIT, Y. MÜLLER, W. (ed) (1998). From School to Work. A Comparative Study of Educational Qualifications and Occupational Destinations. Oxford, Clarendon Press.

STERN, D. WAGNER, D.A. (1999). International Perspectives on the school-to-work transition, Londres, Hampton Press.

TOHARIA, L. (comp.) (1983). El mercado de Trabajo: teoría y aplicaciones, Madrid, Alianza Universidad.

TOHARIA, L. et al. (2001). Flexibilidad, juventud y trayectorias laborales en el mercado de trabajo español, Madrid, CIS.

TORRENTS, D. FACHELLI, S. (2015). "El efecto del origen social con el paso del tiempo: la inserción laboral de los graduados universitarios españoles durante la democracia", Revista Complutense de Educación, 6 (2), 331 - 349. 